\title{
Seismic Design Aids for Buildings Incorporating Soil-flexibility Effect
}

\author{
Koushik Bhattacharya ${ }^{1}$, Sekhar Chandra Dutta ${ }^{2}$ and Rana Roy ${ }^{3}$ \\ ${ }^{1}$ Formerly Graduate Student, Department of Civil Engineering, Bengal Engineering and Science University, India \\ ${ }^{2}$ Professor, Department of Civil Engineering, Bengal Engineering and Science University, India \\ ${ }^{3}$ Lecturer, Department of Applied Mechanics, Bengal Engineering and Science University, India
}

\begin{abstract}
The effect of soil-structure interaction is generally ignored in the design process of low-rise buildings resting on shallow foundations though it has been shown that ignoring such effect may lead to unsafe seismic design. In the present paper, the effect of soil flexibility on base shear and uncoupled torsional-to-lateral natural period ratio, two crucial design parameters in the elastic range, is examined in a comprehensive manner. Variation of such quantities with different influential parameters has been studied considering the effect of soil-flexibility. Apart from reiterating the need significance of soil-flexibility effect for safe seismic design, a large number of rationally derived curves have been presented to incorporate this effect in seismic design with ease and convenience. The exhaustive range of case studies encompassed through such curves may be useful to the designers to easily account for such effect for most of the practically encountered lowrise buildings if needed, through interpolation. Furthermore, the trend observed in such soil flexibility effect is also highlighted to provide physical insight into the issue.
\end{abstract}

Keywords: soil-structure interaction; period ratio; base shear; design guideline

\section{Introduction}

It is postulated in the currently practiced design strategies (Goel and Chopra, 1994) relevant to earthquake-resistant design that the behaviour of the structures will be limited within the elastic range due to moderate level earthquakes, which are very frequent in our countries. It is also well known that low-rise buildings are often used for domestic purpose in developing countries like India. In this context, the performance of low-rise buildings in the event of moderate earthquake needs to be addressed in details. Significant advancement in evaluation of dynamic response of building frames with SSI has been well documented in the literature (e.g., Johnson, 1981; Johnson and Chang, 1991; Johnson and Asfura, 1993). Such review indicates a lack of systematic assessment of the response of low-rise buildings with SSI that can be used directly in design. The present investigation is an attempt to fulfill such want.

For low-rise buildings, generally the lateral natural period is very small and may lie within the sharply increasing acceleration sensitive zone of response spectrum (IS 1893:2002). Hence, an increase in lateral natural period due to the effect of soil-structure interaction may cause an increase in the spectral acceleration ordinate. Moreover, the change of natural

*Contact Author: Sekhar Chandra Dutta, Professor, Department of Civil Engineering, Bengal Engineering and Science University, Shibpur, Howrah 711 103, West Bengal, India

Tel: +91-33-2668-4561 Fax: +91-33-2668-4564

e-mail: scdind2000@yahoo.com

(Received December 30, 2005 ; accepted August 23, 2006) periods may bring the different natural frequencies of the system closer to each other. Considerable increase in seismic base shear under a few specific earthquake data as observed in some recent studies (e.g., Dutta et $a l ., 2004)$ confirms such apprehension. This indicates that a more systematic study based on a design spectrum based response analysis considering the effect of all modes of vibration should be undertaken. This will also eliminate any bias imposed from individual time histories due to their sporadic nature. Such possibilities have also been investigated through systematic observation and comparison of seismic response under a few representative ground motions (both real and synthetic) computed by standard timehistory analysis.

Structures have been exemplified to be torsionally vulnerable if the ratio of the uncoupled torsional-tolateral period ratio $(\tau)$ lies in the critical range of 0.7 $<\tau<1.25$ (Chandler, 1986; Dutta, 1995; Dutta et al., 2000; Kan and Chopra, 1981; Lin and Papageorgiou, 1989; Rosenblueth and Meli, 1986; Whittakar, 1995). The present study, therefore, makes a critical assessment of the seismic base shear and such period ratio, $\tau$ for a range of low-rise buildings incorporating the effect of soil-structure interaction. Variation of such quantities with change in different possible influential factors, for buildings with isolated and grid foundations have been studied and plotted in the form of design curves. The utility of such curves, exhibiting the variation of seismic base shear and torsional-tolateral period ratio $(\tau)$ for any general building frame, is demonstrated through the sample cases of a few building frames. Furthermore, the trends in behaviour 
observed from the results are also presented offering physical insight into the problem.

\section{Idealization of the System}

Buildings have been idealized as three-dimensional space frames using two nodded frame elements. The roof and floor slabs of these buildings are modelled by four nodded plate elements considering the thickness of the slabs. Contribution of the infill wall to the stiffness of the overall structure under lateral loading has been adequately accounted by 'equivalent strut' approach (Smith, 1962) to obtain realistic response. Details of such idealization are available elsewhere (Bhattacharya and Dutta, 2004; Dutta et al., 2004). Response of buildings so idealized has been investigated with and without considering the effect of tie beam attached at the plinth level.

The action of the underlying soil-media has been modeled through a set of springs developed elsewhere (Dobry and Gazetas, 1986; Dobry et al., 1986; Gazetas, 1991) and used in some of the recent studies (Bhattacharyya and Dutta, 2004) as recommended in modern codes (ATC, 1982; FEMA-356, 2000). Expressions of the same are included in Table 1. for convenience. Further details of the same are available elsewhere (Bhattacharyya and Dutta, 2004; Dutta et al., 2004).

To obtain the values of stiffness of the springs for varieties of clayey soil, values of shear modulus $(G)$ of soil have been estimated following the empirical relationship $G=120 N^{0.8}\left(\mathrm{~T} / \mathrm{ft}^{2}\right)$ (Ohsaki and Iwasaki, 1973), where $N$ is the number of blows to be applied in Standard Penetration Test (SPT) of the soil; and Poisson's ratio $(v)$ of soil has been taken to be equal to 0.5 for all types of clay (IS 5249:1992, 1992). $N$ is taken as $1,3,6,12,22$ and 30 for very soft, soft, medium, stiff, very stiff and hard soil, respectively; following the range of ' $N$ ' values prescribed in the literature (Murthy, 1993). Appropriate foundation dimension for the estimation of such stiffness quantities have been arrived at on the basis of standard soil parameters compatible with ' $N$ ' value as listed elsewhere (Dutta et al., 2004) and the relevant guideline available in the literature (ACI committee 436, 1966; ACI committee 336, 1988; IS: 8009-1976 (Part I), 1976; IS 6403:1981; 1981).

It is perceived that stiffness of the equivalent soil springs and hence the influence of SSI is dependent on the frequency of the ground excitation. This frequency dependence may be accounted by multiplying the equivalent spring stiffness by a frequency dependent factor plotted as a function of a non-dimensional parameter $a_{0}$ where $a_{0}=\omega B / V_{s}$ (Gazetas, 1991). Here, $\omega$ is the frequency of the forcing function, $B$ half width of the footing and $V_{s}$ is the shear wave velocity in soil medium. However, it is advocated in the advanced code (FEMA-356, 2000) that the influence of such frequency dependency on the seismic behaviour of low-rise buildings is marginal and may be ignored for practical purpose. In this context, the effect of such frequency dependency has been examined in the present study in limited form.

To this end, a typical 2bay-2bay-2storey building frame with isolated footing has been analyzed for $a_{0}$ $=0.0$ and $a_{0}=1.5$, where the frequency dependent multipliers become maximum and minimum, respectively (Bowles, 1996; Gazeats, 1991). For foundations with high aspect ratio, it is observed that stiffness of the equivalent springs in different directions do not attain corresponding maximal and minimal values simultaneously. However, $\mathrm{K}_{\text {vertical }}$ becomes maximum at $a_{0}=0.3$ while $\mathrm{K}_{\text {lateral }}$ reaches its maximal and minimal at $a_{0}=1.5$ and 0.0 , respectively. Hence, a typical 4bay-4bay-3storey building frame with grid foundation has been analyzed corresponding to $a_{0}=0.0,0.3$ and 1.5. In all these cases, at different values of $a_{0}$, corresponding modifications in stiffness of the equivalent soil springs in all other directions have been suitably incorporated.

With this idealization of structure and soil, natural periods are determined from traditional eigen value problem using subspace iteration technique. Seismic analysis of building frames in the elastic range, both with and without soil-structure interaction effect has been carried out under the design spectrum furnished in IS: 1893-2002 by CQC method (Gupta, 1990). Five percent of critical damping in each mode of vibration is considered. However, soil damping may be significantly high for soils with low-plasticity and at high strain level (Vucetic and Dobry, 1991), which is beyond the scope of the present investigation. Radiation damping may also become insignificant in soils where shear modulus increases sufficiently in the radial direction (Wolf and Song, 2002). Experimental studies on full-scale buildings (Satake et al., 2003) suggest that the overall damping of the buildings are

Table 1. Expression for Stiffnesses of Equivalent Springs along Various Degrees of Freedom (Gazetas, 1991)

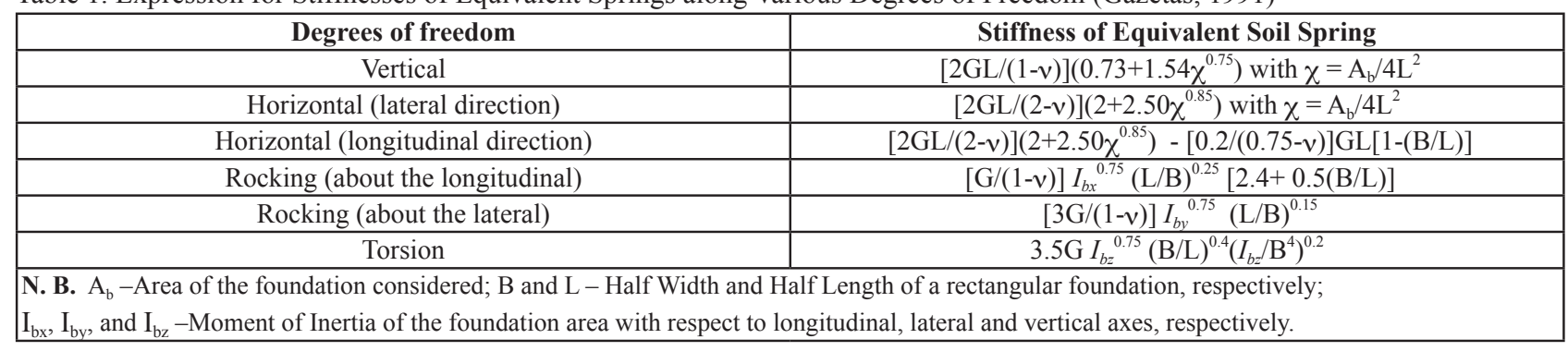


generally within a limit of $8 \%$ of critical damping for $R / C$ structures and $5 \%$ of critical damping for steel structures. Further discussion justifying the consideration of such damping for the soilstructure-foundation system is available elsewhere (Bhattacharyya et al., 2004).

\section{Results and Discussions}

This section presents the change in base shear and fundamental torsional-to-lateral period ratio as a function of various influential parameters for building frames with brick-infill resting on isolated and grid foundation. Such change in response due to the effect of soil-flexibility compared to the same at fixed base condition has been expressed as percentage of the response at fixed base condition. A positive value of change so obtained indicates an increase, while the negative one implies a decrease of the corresponding response parameter. Building frames with brick in-fill having significant stiffness may exhibit considerable increase in natural period due to the effect of soilstructure interaction as manifested under specified acceleration histories elsewhere (Dutta et al., 2004). This suggests the immediate need of design curves to account for such effect in routine design, as ignoring the same may hamper safety. In this context, the present paper primarily aims at preparing design curves

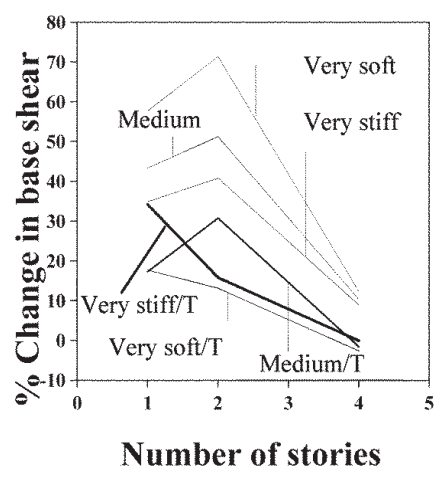

(a)

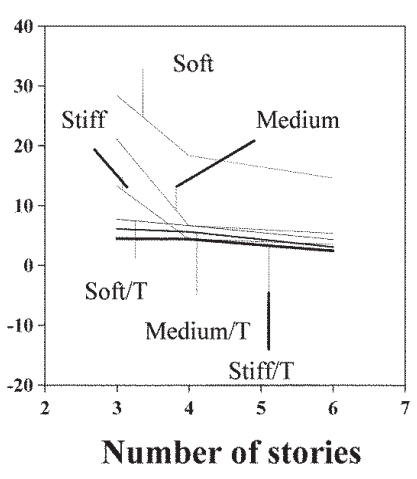

(b) through exhaustive case studies in order to account for the influence of soil-flexibility in the elastic range response. The curves corresponding to the frames with tie beams at plinth level are marked by the letter ' $\mathrm{T}$ ', while those corresponding to the frames without tie beams are not marked. Similarly, figures containing separate curves corresponding to building frames resting on different types of soil are labeled with the corresponding soil types, namely, very soft, soft, medium, stiff and very stiff etc.

\subsection{Effect of structural parameters}

Number of stories, number of bays and the ratio of column to beam stiffness may influence the overall framing action of the structure. Hence, extensive research effort has been made to investigate the effect of these parameters on the overall dynamic behaviour of the system. Fig.1.a and Fig.1.b present the change of base shear with the changes in number of stories for 2bay-2bay building frames with isolated footing and 4bay-4bay building frames with grid foundation resting on various types of soil. It is observed that such change may vary from $10 \%$ to $70 \%$ for frames without ties and from $35 \%$ to even less than $0 \%$ for frames with ties due to variation of number of stories in buildings with isolated footings. On the other hand, corresponding changes in base shear for buildings with grid foundations are found to vary within a range of

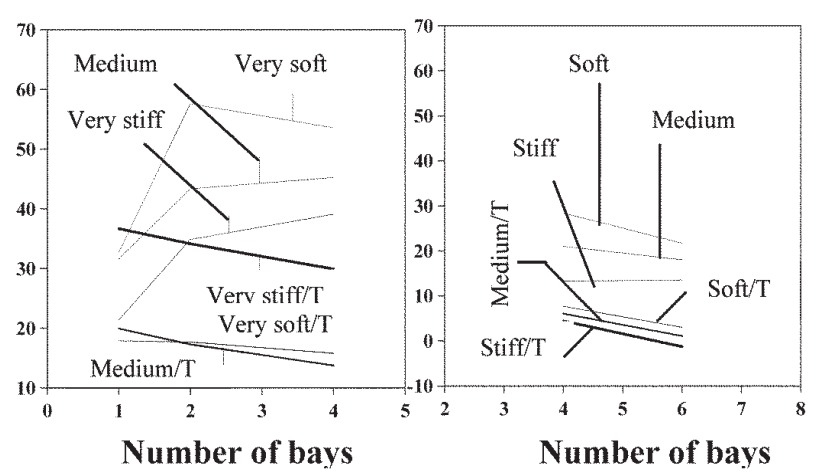

(c)

(d)

Fig.1. Variation of Percentage Changes in Base Shear for (a) 2 Bay 2 Bay Building Frame with Isolated Footing, and (b) 4 Bay 4 Bay Building Frame with Grid Foundation, (c) 1 Storey Building Frame with Isolated Footing and (d) 3 Storey Building Frame with Grid Foundation

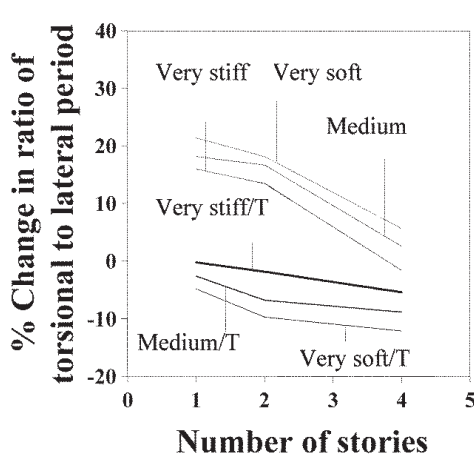

(a)

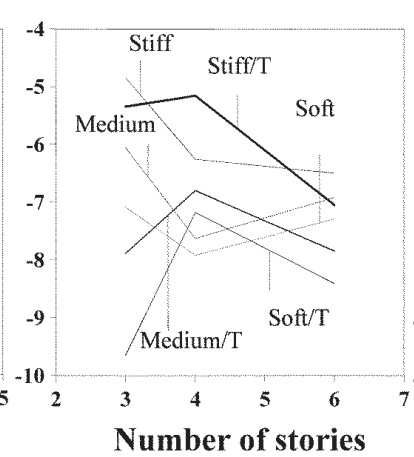

(b)

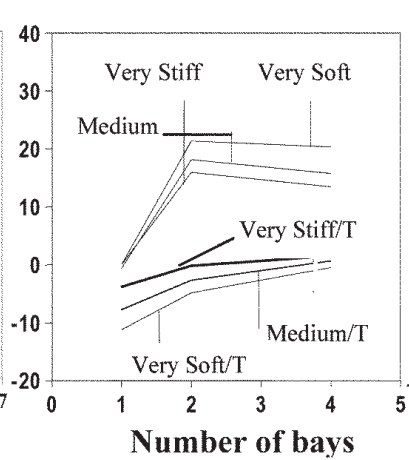

(c)

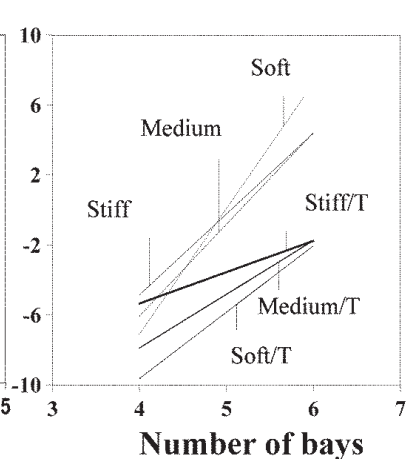

(d)

Fig.2. Variation of Percentage Changes in Ratio of Fundamental Torsional to Lateral Natural Period for (a) 2 Bay 2 Bay Building Frame with Isolated Footing, (b) 4 Bay 4 Bay Building Frame with Grid Foundation, (c) 1 Storey Building Frame with Isolated Footing and (d) 3 Storey Building Frame with Grid Foundation 
$4 \%$ to $30 \%$ due to change in number of stories. The figures clearly indicate that the effect of soil-structure interaction on the change in base shear generally decreases with increase in number of stories. Hence, to analyze the effect of variation of number of bays, out of several case studies, results corresponding to 1storey building frame with isolated footing and 3storey frame with grid foundation have been presented to exhibit the maximum possible effect of soil-structure interaction. For buildings with isolated footings, number of bays has been varied as 1,2 and 4; while for buildings with grid foundation, cases corresponding to 4 and 6 bays are presented. The percentage change in base shear has been presented in Fig.1.c and Fig.1.d as a function of number of bays, for buildings with isolated and grid foundation, respectively. Figures show that the variation in number of bays may result in a change of response in the order of about $60 \%$ in case of building frames with isolated footing resting on very soft clay, while a maximum change of $30 \%$ is observed for buildings with grid foundation constructed on soft clay. Effect of column to beam stiffness has been examined considering the practically feasible range (0.25-4) of variation of such parameter. The influence of the same to alter the effect of soil-structure interaction is found subdued; hence the results are not included for brevity.

Change in fundamental torsional-to-lateral period ratio due to soil-flexibility is studied for similar

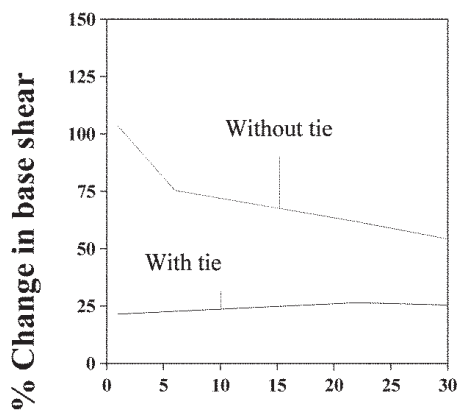

$\mathbf{N}$ Value of clay

1 bay 1 bay 2 storey

(a)

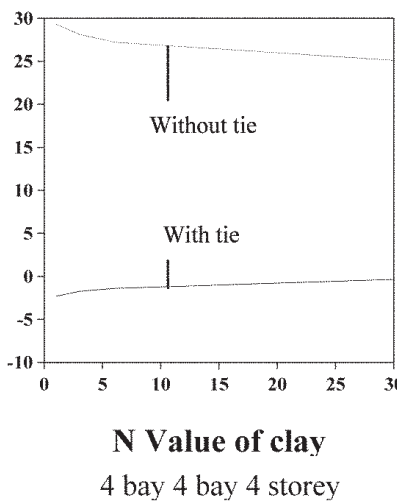

(a) systems in order to assess the torsional vulnerability of a structure. Fig.2.a presents the variation of change in such period ratio with variation in number of stories for the building frames with isolated footing, while Fig.2.b shows the same for the building frames with grid foundations. Such change is found to vary over a range of about $-10 \%$ to $20 \%$ for buildings with isolated footing and $-5 \%$ to $-10 \%$ for buildings with grid foundations. Such changes gradually diminish due to the increase in number of stories. Hence, the effect of number of bays in altering such quantity has been presented, corresponding to 1 storey building with isolated footing and 3storey building with grid foundation in Fig.2.c and Fig.2.d, respectively. For buildings with isolated footings, the maximum change in period ratio for frames without tie beams may be as high as about $20 \%$, while, for frames with tie beams, the same is in the order of $-10 \%$ only. Such quantity is found to undergo a change of about $8 \%$ and $-10 \%$ for frames without and with tie beams, respectively in case of buildings resting on grid foundation. Change in such quantity with change in ratio of column to beam stiffness is not found appreciable (maximum about $5 \%$ ), and hence not presented in the limited scope of this paper.

Thus the curves furnished may be utilized to assess the influence of soil-structure interaction in real design. Number of storeys and bays is found to play important

Fig.3. Variation of Percentage Changes in Base Shear for Building Frames with (a) Isolated Footing and (b) Grid Foundation

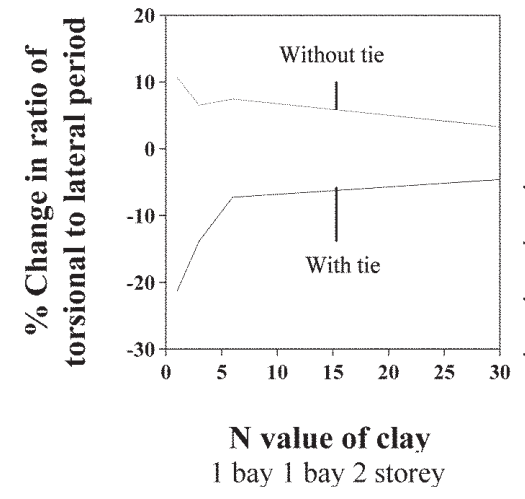

(a)

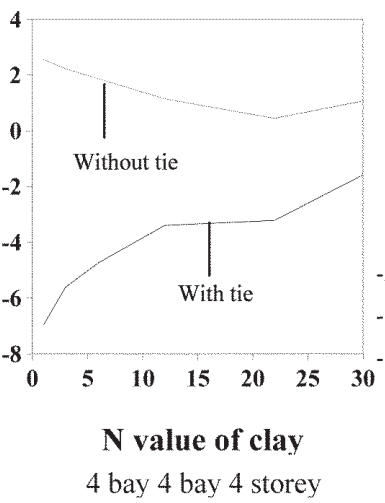

(a)

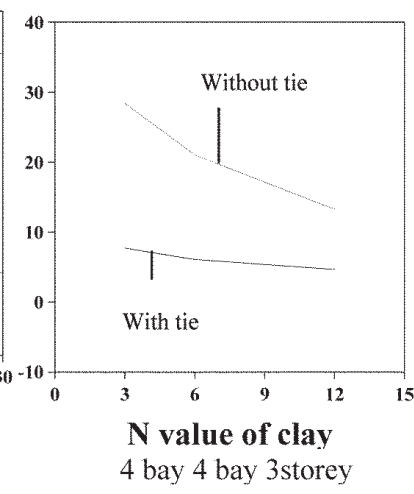

(b)

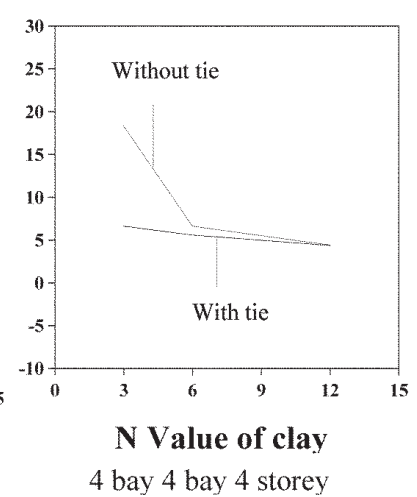

(b)

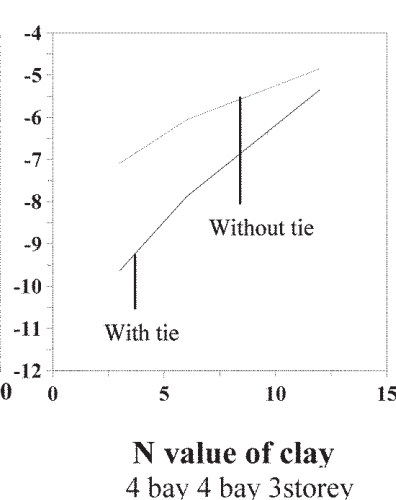

(b)

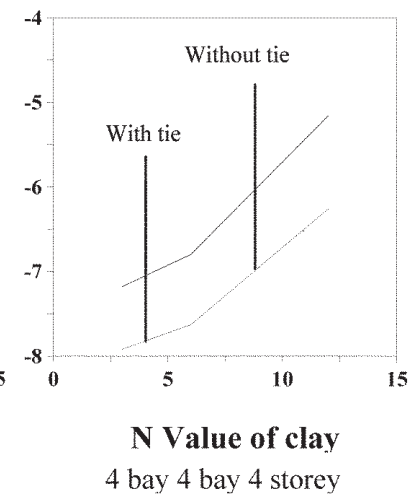

(b)

Fig.4. Variation of Percentage Changes in Ratio of Fundamental Torsional to Lateral Natural Period for Building Frames with (a) Isolated Footing and (b) Grid Foundation 

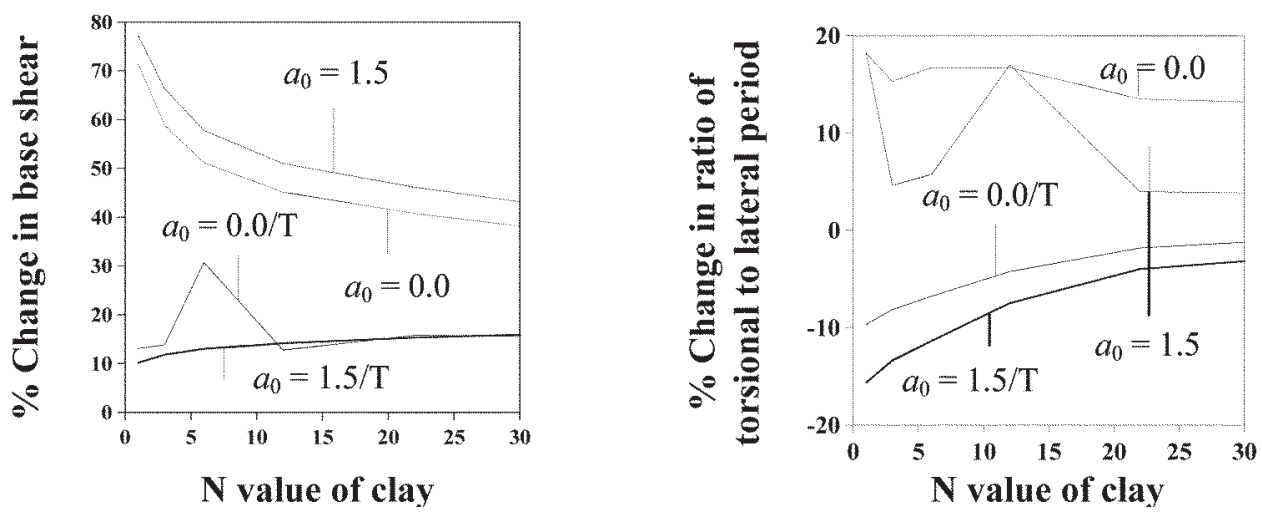

Fig.5. Influence of Variation of Excitation Frequency on Seismic Response and Dynamic Characteristics of Low-rise Buildings

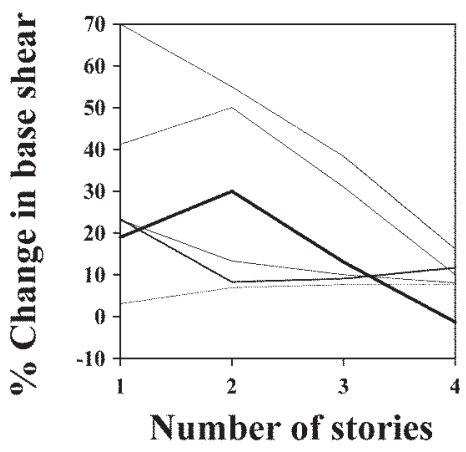

(a)

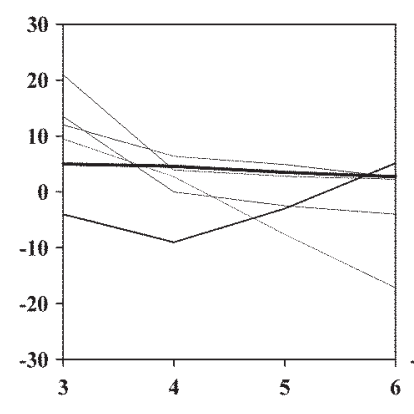

Number of stories

(b)

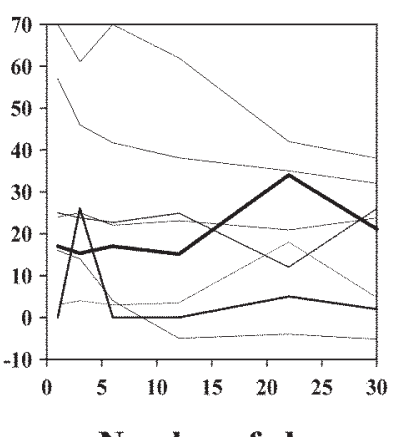

(c)

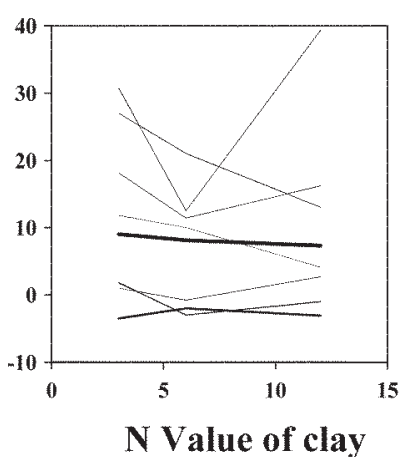

(d)

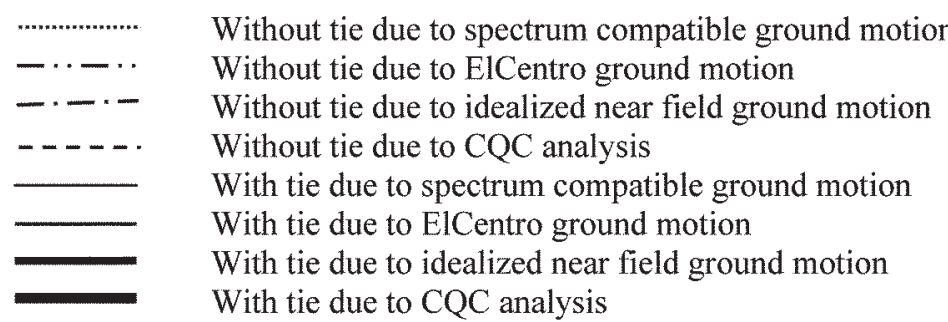

Fig.6. Variation of Percentage Changes in Base Shear for (a) 2 Bay 2 Bay Building Frame with Isolated Footing, (b) 4 Bay 4 Bay Building Frame with Grid Foundation Resting on Medium Soil, (c) 2 Bay 2 Bay 1 Storey Building Frame with Isolated Footing, and (d) 4 Bay 4 Bay 3 Storey Building Frame with Grid Foundation Resting on Medium Soil

role in altering such influence. Effect of soil-flexibility seems significant, particularly in case of low-rise systems having considerable lateral stiffness compared to the same offered by soil.

\subsection{Effect of subsoil parameters}

Influence of variation of subsoil properties is examined by considering various subgrade characteristics and the structural systems as detailed earlier. For buildings with grid foundation, very soft and very stiff soil conditions have not been considered from the standpoint of practical feasibility. Impact of subsoil characteristics on the seismic base shear and period ratio have been presented in Fig.3. and Fig.4., respectively in terms of $N$ value of different types of soil. For buildings with isolated footings, the maximum increase in base shear is around $100 \%$ for 1bay-1bay- 2 storey building frame without tie beam, while for frames with tie beams, the maximum change may be on the order of $25 \%$, even sometimes about $35 \%$. For buildings with grid foundation, a maximum increase of about $30 \%$ in base shear is observed for 4bay-4bay- 3storey building frame without tie beam, while the same reduces to the order of $8 \%$ due to the addition of tie beam. The results generally exhibit a gradually diminishing influence of soil-structure interaction with increasing hardness of soil. Addition of tie beam reduces the increase in base shear and sometimes (for 4storey system with isolated footing), reduces from what is obtained at the fixed base condition. Introduction of tie beam effectively transfers the wall load at ground storey level resting on it to the foundation leading to an increase in foundation size. Hence, this enhances the stiffness of the equivalent springs representing the soil behaviour. However, as expected, such influence reduces with increase in number of storeys.

Influence of soil-flexibility on fundamental torsional-to-lateral period ratio has been examined for all the systems mentioned. A maximum increase of about $22 \%$ is observed for 2 bay-2bay-1 storey building without tie beam, while maximum decrease of about $22 \%$ is observed for 1 bay-1bay-2storey 
building with tie beam. However, for buildings with grid foundations, such changes are always negative, unlike the similar response for buildings with isolated footings, irrespective of the nature of the clay. Such decrease is observed to be in the order of maximum $10 \%$ as exhibited in Fig.4.b. Results of a 4bay-4bay4storey building frame resting on isolated footing have also been presented in Fig.4.a to compare the results of a similar building frame with grid foundation shown in Fig.4.b. This shows that the order of change in fundamental torsional-to-lateral natural period ratio is comparable. However, buildings without tie beams exhibit an increase if they have isolated footings, while those with grid foundation always show a decrease in torsional-to-lateral period ratio, due to soil-flexibility.

The effect of the frequency-dependent soil stiffness has been studied for some critical values of $a_{0}$ as described earlier for buildings with isolated and grid footing. Results corresponding to the buildings frames on isolated footing as presented in Fig.5. exhibits a maximum change in base shear in the order of about $80 \%$ and $12 \%$ for $a_{0}=1.5$, while the same is observed to be around $70 \%$ and $30 \%$ for $a_{0}=0$, for buildings without and with tie beam, respectively. The results corresponding to the frequency independent behaviour of soil, i.e., $a_{0}=0.0$ has been included for the sake of comparison. This shows that the effect of frequency of the forcing function may moderately influence the seismic behaviour of the system. However, the effect of such frequency dependent factors becomes subdued if tie beam is introduced in the building frame. Hence, such effect may be considered in order to analyze the important structures to achieve a more accurate estimate of design base shear. Fig.5. also shows that the change in torsional-to-lateral period ratio does not vary by more than $10 \%$ due to such frequency dependency. Such results for buildings with grid foundations, conforming to the observation for buildings with isolated footing, are not included in the limited scope of the present paper.

\section{Applicability of Design Curves}

The curves presented in this paper showing the variation of the design parameters of interest, have emerged from CQC analysis under the design spectrum specified in the IS: 1893:2002. However, such response may be sensitive to the ground motion characteristics. To investigate this issue, percentage change in base shear with the most sensitive parameter of superstructure, viz., number of storey and that of the sub-soil, viz., $N$ value, due to various representative ground motions have been compiled from a previous work of the authors (Dutta et al., 2004). Such variation in response with number of storey obtained under synthetic spectrum consistent ground motion as well as El Centro earthquake data and with change in $N$ value obtained due to the same ground motion data as well as idealized near-field earthquake data, have been presented in Fig.6. Variation in response obtained through CQC analysis under the code-specified design spectrum is also superimposed for comparison. A critical observation of the results presented offers the impression that the response due to a particular earthquake may often yield a very high strength demand. Nevertheless, the design should not be guided by the sporadic nature of individual earthquake. In absence of statistical information extracted from the results obtained under several ensembles of earthquake data, outcome of CQC analysis, based on the design spectrum should be considered for real-life design. Here lies the need and applicability of the design curves presented in this paper.

The variation curves presented in this paper showing change in base shear and torsional-to-lateral natural period ratio may be used exhaustively as seismic design aids. These may also be utilized through linear interpolation to estimate the changed base shear and period ratio of other buildings (whose curves are not specifically plotted in the variation curves) on the basis of the same obtained at fixed base condition of the system under consideration. Results furnished in Table 2. and Table 3. comparing base shear and torsionalto-lateral natural period ratio for structures obtained through rigorous analysis and using variation curves demonstrate the same. Variation curves presented may also be utilized in predicting the base shear for buildings irregular in plan. It is better to consider the maximum percentage increase in base shear in the regular frames of possible closer configuration. For the design curves presented, maximum percentage increase in base shear due to soil-flexibility for such possible system may be achieved and the maximum increase amongst the same is to be adopted. Base shear obtained for the irregular building frames at fixed base condition should then be increased by the same amount to arrive at the base shear of the irregular building frame with soil-structure interaction. Such capacity of the design curves has been explained through the consideration of a 2 storey frame having partially two bays and partly one bay in two mutually perpendicular directions. 1bay-1bay-2storey and 2bay-2bay-2storey systems are considered as regular frames of which the latter exhibits higher percentage increase in base shear due to soil-flexibility. Hence, to account for the soilstructure interaction on this irregular frame, base shear obtained for the same at fixed-base condition has been increased by a percentage equal to the same observed for 2 bay-2bay-2storey frame. Irregular frame has also been analyzed through rigorous modelling with soil-structure interaction effect, and the results have been compared. A maximum deviation of only $8 \%$ is observed for frames on very soft soil. Hence, these curves can be effectively used for estimating the design base shear of irregular buildings with incorporation of the effect of soil-structure interaction. 
Table 2. Performance of the Variation Curves in Predicting Base Shear of Building Frames, with Isolated Footing

\begin{tabular}{|c|c|c|c|c|}
\hline Frame Type & Soil Type & $\begin{array}{c}\text { Base shear Actual } \\
\mathbf{( k N )}\end{array}$ & $\begin{array}{c}\text { Base shear Interpolated } \\
\mathbf{( k N )}\end{array}$ & $\begin{array}{c}\text { \% } \\
\text { Deviation }\end{array}$ \\
\hline $\begin{array}{c}\text { 2 Bay 2 Bay 3 Storey (Without Tie } \\
\text { Beam) }\end{array}$ & Very Soft & 4158.16 & 4014.83 & -3.45 \\
\hline \multirow{2}{*}{ 2 Bay 2 Bay 3 Storey (With Tie Beam) } & Very Soft & 4996.70 & 4845.20 & -3.03 \\
\cline { 2 - 5 } & Medium & 5047.35 & 5035.10 & -0.24 \\
\cline { 2 - 5 } & Very Stiff & 5124.26 & 4934.21 & -3.71 \\
\hline \multirow{2}{*}{ 3 Bay 3 Bay 1 Storey (With Tie Beam) } & Very Stiff & 3374.55 & 3527.42 & 4.53 \\
\hline $\begin{array}{c}\text { Irregular, partly 2 Bays and partly 1 } \\
\text { Bay in both the directions, 2 Storey } \\
\square\end{array}$ & Very Soft & 1807.17 & 1951.81 & 8.00 \\
\cline { 2 - 5 } & Mithout Tie Beam & 1646.68 & 1682.60 & 2.18 \\
\hline & Very Stiff & 1615.72 & 1550.82 & -4.02 \\
\hline
\end{tabular}

Table 3. Performance of the Curves in Predicting Torsional to Lateral Time Period Ratio of Building Frames

(a) Building frames with isolated footing

(b) Building frames with grid foundation

\begin{tabular}{|c|c|c|c|c|c|c|c|c|c|}
\hline $\begin{array}{l}\text { Frame } \\
\text { Type }\end{array}$ & $\begin{array}{l}\text { Soil } \\
\text { Type }\end{array}$ & $\begin{array}{c}\mathrm{T}_{\theta} / \mathrm{T}_{\mathrm{x}} \\
\text { Actual }\end{array}$ & $\begin{array}{c}\mathbf{T}_{\theta} / \mathbf{T}_{\mathbf{x}} \\
\text { Interpolated }\end{array}$ & $\begin{array}{c}\% \\
\text { Deviation }\end{array}$ & $\begin{array}{l}\text { Frame } \\
\text { Type }\end{array}$ & $\begin{array}{l}\text { Soil } \\
\text { Type }\end{array}$ & $\begin{array}{c}\mathbf{T}_{\theta} / \mathbf{T}_{\mathbf{x}} \\
\text { Actual }\end{array}$ & $\begin{array}{c}\mathbf{T}_{\theta} / \mathbf{T}_{\mathbf{x}} \\
\text { Interpolated }\end{array}$ & $\begin{array}{c}\% \\
\text { Deviation }\end{array}$ \\
\hline \multirow{3}{*}{$\begin{array}{c}2 \text { Bay } 2 \\
\text { Bay } \\
3 \text { Storey } \\
\text { Without } \\
\text { Tie Beam }\end{array}$} & Very Soft & 0.5572 & 0.5735 & 2.90 & \multirow{3}{*}{$\begin{array}{c}4 \text { Bay } 4 \\
\text { Bay } \\
5 \text { Storey } \\
\text { Without } \\
\text { Tie Beam }\end{array}$} & Soft & 0.5111 & 0.4962 & -3.01 \\
\hline & Medium & 0.5360 & 0.5598 & 4.40 & & Medium & 0.4950 & 0.4978 & 0.56 \\
\hline & $\begin{array}{l}\text { Very } \\
\text { Stiff }\end{array}$ & 0.5235 & 0.5385 & 2.90 & & Stiff & $\begin{array}{c}0.5009 \\
9\end{array}$ & 0.5020 & 0.22 \\
\hline \multirow{3}{*}{$\begin{array}{c}3 \text { Bay } 3 \\
\text { Bay } \\
1 \text { Storey } \\
\text { With Tie } \\
\text { Beam }\end{array}$} & Very Soft & 0.8725 & 0.8677 & -0.60 & \multirow{3}{*}{$\begin{array}{c}4 \text { Bay } 4 \\
\text { Bay } \\
5 \text { Storey } \\
\text { With Tie } \\
\text { Beam }\end{array}$} & Soft & 0.6516 & 0.6496 & -0.30 \\
\hline & Medium & 0.8844 & 0.8855 & 0.12 & & Medium & 0.6563 & 0.6524 & -0.60 \\
\hline & $\begin{array}{l}\text { Very } \\
\text { Stiff }\end{array}$ & 0.8954 & 0.9034 & 0.88 & & Stiff & 0.6625 & 0.6630 & 0.07 \\
\hline
\end{tabular}

\section{Conclusions}

The present investigation, conducted toward formulating direct design guideline for low-rise systems accounting SSI, computes the response based on codespecified design spectrum in the elastic domain. Dynamic characteristics of the structures with various numbers of bays, stories etc. are computed to assess seismic vulnerability of low-rise buildings with isolated footings and grid foundation. The results of the study may lead to the following broad conclusions:

1. The effect of soil-structure interaction may cause considerable increase in seismic base shear of low-rise building frames, particularly those with isolated footings. This may be attributable to the increase in spectral acceleration associated with an increase in period in the short period region. In this context, it is understood that a converse trend pertaining to the impact of SSI is expected for systems having period in the long-period range, as elucidated elsewhere in details (Dutta et al. 2004). Such observation also conforms to codal recommendations (ATC, 1982). This emphasizes the adverse impact of soilstructure interaction for low-rise buildings in particular.

2. Fundamental torsional-to-lateral natural period ratio, which regulates the seismic torsional response arising out of lateral-torsional coupling, may be appreciably altered due to SSI. Thus, evaluation of this parameter without considering soil-structure interaction may cause serious error in seismic design, as the seismic torsional response is found to be sensitive, particularly when this ratio is close to 1 (Dutta, 1995; Kan and Chopra, 1991).

3. The impact of SSI on base shear as well as on period ratio is in general pronounced if the structure does not have tie beam, irrespective of whether the building frame is supported by isolated or grid foundation. The effect is further aggravated with decreasing hardness of soil and number of stories of building frames. Hence, this effect needs to be considered very seriously, at least in these cases.

4. The influence of soil-structure interaction on the overall seismic response is not appreciably altered even if a grid foundation is provided instead of isolated footings. This is evident from comparison of the results for two building frames having isolated footing and grid foundation, respectively while being exactly similar in other aspects and parameters. The larger changes observed for building frames with isolated footings are primarily due to lesser number of stories of these frames, for which this type of foundation is considered suitable.

5. Excitation frequency of the ground motion may influence the effect of soil-structure interaction on base shear to a limited extent. Hence, this effect should be considered for very important structures only. However, 
the consequence of the effect of excitation frequency on fundamental torsional-to-lateral period ratio needs to be considered if the period ratio is in the range of $0.7-1.25$, as the seismic torsional vulnerability is extremely sensitive in this range of period ratio (Dutta, 1995; Kan and Chopra, 1991).

Inferences drawn above related to the seismic base shear of the building frames are concordant to the trend observed elsewhere (Dutta et al., 2004).

6. Design curves presented for some regular building frames may be used to estimate design shear and period ratio through linear interpolation. Based on limited observation, it seems that such curves may also be used to assess design base shears for buildings irregular in plan resting on isolated footing, using the procedure detailed in the present paper. However, the same needs to be further verified through more comprehensive case studies.

7. Buildings on grid foundation do not exhibit variation in base shear over a wide range. A maximum increase in base shear is observed to be on the order of $30 \%$ and $10 \%$ for such systems with and without tie beams. Thus, the consideration of a multiplication factor of 1.3 for the base shears of these building frames without tie beams and a mere 1.1 for the base shear of the same with tie beams may be sufficient to ensure safety in the design. However, if the grid foundation is provided for 1storey or 2 storey buildings, effect may be higher.

The study, as a whole, attempts to identify the nature of influence of various parameters regulating the effect of soil-structure interaction on both the base shear and torsional-to-lateral period ratio of low-rise building frames. A large number of curves exhibiting variation of these two parameters for typical sample cases can help the designer to assess the effect of soil-structure interaction on these two important dynamic characteristic parameters, at least for preliminary seismic design, and to identify the cases expected to exhibit pronounced vulnerability by ignoring the influence of soil-structure interaction in the process of design.

\section{Acknowledgment}

The authors gratefully acknowledge the support rendered by a Research Project sanctioned by Council of Scientific and Industrial Research, Government of India [No. 22(0347)/02/EMR-II] towards the successful completion of the present work.

\section{References}

1) ACI Committee 436, (De Simone, S.V. (Ch)) (1966), Suggested design procedures for combined footings and mats, Journal of the American Concrete Institute, 63(10), pp.1041-1057.

2) ACI Committee 336, (Ulrich, J. (Ch)) (1988), Suggested analysis and design procedures for combined footings and mats, Journal of the American Concrete Institute, 86(1), pp.304-324.

3) Tentative Provisions for the Development of Seismic Regulations for Buildings, Applied Technology Council, NSF \& NBS, 1982.

4) Bhattacharya, K., and Dutta, S.C. (2004), Assessing lateral period of building frames incorporating soil-flexibility, J. Sound and Vibration, 269 (3-5), pp.795-821.

5) Bhattacharya, K., Dutta, S.C., and Dasgupta, S. (2004), Effect of soilflexibility on dynamic behaviour of building frames on raft foundation. $J$. Sound and Vibration, 274, pp.111-135.

6) Bowles, J.E. (1996), Foundation analysis and design, McGraw-Hill International Editions, $5^{\text {th }}$ edition, Civil Engineering Series.

7) Chandler, A.M. (1986), Building damage in Mexico City earthquake, Nature, 320(6062), pp.497-501.

8) Dobry, R., and Gazetas, G. (1986), Dynamic response of arbitrarily shaped foundations, Journal of Geotechnical Engineering Division, ASCE, 112(2), pp.109-135.

9) Dobry, R., Gazetas, G., and Stokoe, K.H. (1986), Dynamic response of arbitrarily shaped foundations: Experimental verifications, Journal of Geotechnical Engineering Division, ASCE, 112(2), pp.136-154.

10) Dutta, S.C. (1995), Torsional behaviour of elevated water tanks with reinforced concrete frame-type stagings during earthquake, Ph.D. thesis, Department of Civil Engineering, Indian institute of Technology, Kanpur, India.

11) Dutta, S.C., Murthy, C.V.R. and Jain, S.K. (2000), Seismic torsional vibration in elevated tanks, Structural Engineering and Mechanics, 9(6), pp.615-636.

12) Dutta, S.C., Bhattacharya, K., and Roy, R. (2004), Response of low-rise buildings under seismic ground excitation incorporating soil-structure interaction, Soil Dynamics and Earthquake Engineering, 24, pp.893-914.

13) Federal Emergency Management Agency (FEMA), Prestandard and Commentary for the seismic rehabilitation of buildings, Federal Emergency Management Agency. Report No. FEMA-356, Washington D.C., USA, 1992, 2000.

14) Gazetas, G. (1991), Formulas and charts for impedances of surface and embedded foundations, Journal of Geotechnical Engineering, ASCE, 117(9), pp.1363-1381.

15) Goel, R.K. and Chopra, A.K. (1994), Dual-level approach for seismic design of asymmetric plan buildings, Journal of Structural Engineering, ASCE, 120(1), pp.161-179.

16) Gupta, A.K. (1990), Response Spectrum Method, Blackwell Scientific Publications, Cambridge, England.

17) Haroun, M.A., and Abou-Izzeddine, W. (1992), Parametric study of seismic soil-tank interaction I: Horizontal excitation, Journal of Structural Engineering Division, ASCE, 118(3), pp.783-797.

18) IS: 8009-1976 (Part I), Indian standard code of practice for calculation of settlement of foundation, Bureau of Indian Standards, New Delhi, India, 1976.

19) IS: $6403-1981$, Indian standard code of practice for determination of bearing capacity of shallow foundation, Bureau of Indian Standards, New Delhi, India, 1981.

20) IS: 5249-1992, Method of test for determination of dynamic properties of soil, Bureau of Indian Standards, New Delhi, India, 1992.

21) IS: 1893-2002, Indian standard criteria for earthquake resistant design of structures, Bureau of Indian Standards, New Delhi, India, 2002.

22) Johnson, J.J. (1981), Soil structure interaction: The status of current analysis methods and research, Lawrence Livermore National Laboratory (LLNL), UCRL-53011, NUREGICR-1780, prepared for the U.S. Nuclear Regulatory Commission, Washington, D.C.

23) Johnson, J.J., and A.P. Asfura. (1993), Soil structure interaction (SSI): Observations, data and correlative analysis, in Developments in dynamic soil-structure interaction, P. Gulkan and R.W. Clough, eds. Kluwer Academic Publishers, Dordrecht, pp.219-258.

24) Johnson, J.J., Chang, C.-Y. (1991), State of the art review of seismic input and soil-structure interaction, Appendix E in A Methodology for Assessment of Nuclear Power Plant Seismic Margin (Rev. 1), EERI NP6041-SL, Electric Power Research Institute, Palo Alto, Ca.

25) Kan, C.L., and Chopra, A.K. (1981), Torsional coupling and earthquake responses of simple elastic and inelastic systems, Journal of Structural Divisions, ASCE, 107(ST-8), pp.1569-1587.

26) Lin, B.C., and Papageorgiou, A.S. (1989), 'Deformation of torsional coupling caused by closely spaced periods, 1984 Morgan Hill earthquake response of the Santa Clara country building, Earthquake Spectra, 5(3), pp.539-556.

27) Murthy, V.N.S. (1993), Soil Mechanics and Foundation Engineering, Dhanpat Rai, New Delhi, India.

28) Ohsaki, Y., and Iwasaki, R. (1973), On dynamic shear moduli and Poisson's ratio of soil deposits, Soils and Foundations, 13(4).

29) Parmelee, R.A. (1967), Building-foundation interaction effects, Journal of Engineering Mechanics Division, ASCE, 93(EM-2), pp.131-152.

30) Rosenblueth, E., and Meli, R. (1986), The 1985 earthquake: Causes and effects in Mexico City, Concrete International, 8, pp.23-34.

31) Roy, R., and Dutta, S.C. (2001), Effect of soil-structure interaction on dynamic behaviour of building frames on grid foundations, Proc., Structural Engineering Convention (SEC 2001), October 29-31, Roorkee, India, pp.694-703.

32) Roy, R., Dutta, S.C., and Moitra, D. (2001), Effect of soil-structure interaction on dynamic behaviour of building frames on isolated footings, Proc., National Symposium on Advances in Structural Dynamics and Design (ASDD), January 9-11, Chennai, India, pp.579-586.

33) Satake, N., Suda, K., Arakawa, T., Saraki, A., and Tamura, Y. (2003), Damping evaluation using full-scale data of buildings in Japan, $J$. Structural Engineering, ASCE, 129(4), pp.470-477.

34) Smith, B.S., Lateral stiffness of in filled frames (1962), J. Structural Engineering, ASCE; 88 (ST6): pp.183-199.

35) Vucetic, M. and Dobry, R. (1991), Effect of soil plasticity on cyclic response Journal of Geotechnical Engineering, ASCE 117, pp.89-107.

36) Whittaker, S. (1995), NSF-EERC Kobe earthquake reconnaissance report, Draft Chapter on Engineered Buildings, Earthquake Engineering Research Centre, University of California, Berkeley, California.

37) Wolf, J.P., and Song, C. (2002), Some cornerstones of dynamic soilstructure interaction, Engineering Structures 24, pp.13-28. 